\title{
Driver Safety Alert System using Machine Learning
}

\author{
Manjusha Sanke \\ S.R.I.E.I.T. \\ Shiroda-Goa
}

\author{
Pranjali Savaikar \\ S.R.I.E.I.T. \\ Shiroda-Goa
}

\author{
Chaitravi Parab \\ S.R.I.E.I.T. \\ Shiroda-Goa
}

\author{
Mangesh Gawas \\ S.R.I.E.I.T. \\ Shiroda-Goa
}

\author{
Viraj Mhalshekar \\ S.R.I.E.I.T. \\ Shiroda-Goa
}

\begin{abstract}
Road accidents majorly occur due to driver fatigue and drowsiness or lack of concentration. A Driver Safety Alert System Using Machine Learning has been introduced for reducing the number of accidents. This system has been developed to support three major modules such as Drowsiness Detection, Lack of Concentration Detection and Mobile Usage Detection. It monitors driver performance by analyzing facial expressions, driver movements and his overall behavior. This system is based on application of Image Processing. Driver's live video is decomposed into frames and image processing is performed on each frame. The main image processing tool used is OpenCV. Python has been used as coding language. Drowsiness Detection has been carried out by estimating eye aspect ratio. Detection of lack of concentration has been done by checking head position. Mobile Usage Detection is based on detection of object near the ear.

A driver's unusual behavior while driving that leads to road accidents has been detected and approaches are proposed to overcome these constraints which include Drowsiness Detection, Lack of Concentration Detection and Mobile Usage Detection.
\end{abstract}

\section{Keywords}

Drowsiness Detection, Lack of Concentration, Mobile usage Detection, OpenCV, EAR, Machine learning, Image processing

\section{INTRODUCTION}

The primary purpose of the Driver safety Alert System is to develop a system that can reduce the number of accidents which are caused due to lack of concentration, drowsiness and also because of distraction such as phone call. The technique which is used for detecting drowsiness of driver is non-intrusive, that is, it is based on visual assessment of driver's bio-behavior from face images. The main focus is on the detection of blinks by estimating the EAR (Eye aspect Ratio). This is achieved by monitoring the eyes of the driver throughout the entire video sequence. EAR is defined as per below formula, where $\mathrm{p} 1, \mathrm{p} 2$....p6 are the eye coordinates.

$$
\mathrm{EAR}=|\mathrm{p} 2-\mathrm{p} 6|+|\mathrm{p} 3-\mathrm{p} 5| /(2 *|\mathrm{p} 1-\mathrm{p} 4|)
$$

For Lack Of Concentration, same technique is used as in the Drowsiness Detection. Here the main focus of the system is to monitor the head position of the driver continuously.

In the third module i.e. Detection Of Mobile Usage, it is important to detect the object or the mobile phone in the hands or anywhere near the ears of the driver. So, here the object detection is done by the system throughout the journey.

\section{PROBLEM DESCRIPTION}

\subsection{Existing System}

There are many industries that have already developed system for detecting the drowsiness of the driver. The existing system provides various features such as detection of lack of concentration, drowsiness and mobile usage while driving. But none of these systems provides all three features in one system.

\subsection{Proposed System}

The proposed system will cover all three modules mentioned below in one system.

- Drowsiness detection(feeling sleepy)

- Mobile usage while driving(distraction)

- $\quad$ Lack of concentration(looking outside)

\section{BACKGROUND RESEARCH}

In [2], a proposed real-time driver alert system aims to detect the driver's eye, calculate a PERCLOS (percentage eye closure) ratio, and evaluate the driver's eyes condition, using a Raspberry Pi camera mounted on a Raspberry Pi 3 . When the PERCLOS ratio exceeds a threshold, an alert system installed, in the form of a medium loud beeping sound, is switched-on. Accuracy of the proposed algorithms is $83.38 \%$.

In [4], an algorithm is developed for extracting characteristics allowing the cell phones identification used during driving a vehicle. The pre-processing step is tasked to find the region of interest, i.e., the face of the driver. The segmentation is based on locating pixels of the skin of the driver present in the preprocessed image.

In [3], a method has been proposed that utilizes deep learning based object detection method in the subtasks of the cell phone violation detection process; windshield region detection, driver detection and phone usage detection. It was having overall accuracy of $90.8 \%$.

In [5], author presents a way to analyze and anticipate driver drowsiness by applying a Recurrent Neural Network over a sequence frame driver's face. They used a dataset to shape and implemented repetitive neural network architecture multilayer model-based 3D Convolutional Networks to detect driver drowsiness.

In [8], the proposed algorithm processes live video feed focused on the driver's face and tracks his eye and mouth movements to detect eye closure and yawning rates. An alarm sounds if the driver is drowsy or already asleep. Haar-cascade classifiers run parallel on the extracted facial features to detect 
eye closure and yawning. Yawn detection. Lip distance is the parameter used to determine if the subject's mouth is open. Accuracy of proposed algorithm is $85 \%$.

Table 1. Comparison of various techniques used

\begin{tabular}{|c|c|c|c|c|}
\hline Paper & Methodology & Technology & Dataset & Accuracy \\
\hline [2] & $\begin{array}{l}\text { Face } \\
\text { detection, } \\
\text { Eyes } \\
\text { Detection, } \\
\text { Calibration, } \\
\text { Drowsiness } \\
\text { Detection, } \\
\text { Inattention } \\
\text { Alert }\end{array}$ & $\begin{array}{l}\text { Python } \\
\text { openCv } \\
\text { Dlib(facial } \\
\text { landmark) } \\
\text { Raspberry pi }\end{array}$ & $\begin{array}{l}\text { Normal } \\
(1680) \\
\text { With } \\
\text { eyeglasses } \\
(1620) \\
\text { with } \\
\text { sunglasses } \\
(1470) \\
\text { With cap/hat } \\
(1650) \\
\text { With mask } \\
(1620)\end{array}$ & $83.38 \%$ \\
\hline [4] & $\begin{array}{l}\text { Support } \\
\text { Vector } \\
\text { Machines, } \\
\text { Acquisition, } \\
\text { Pre-processing } \\
\text { Segmentation, } \\
\text { Extraction of } \\
\text { features }\end{array}$ & $\begin{array}{l}\text { Python, } \\
\text { Support } \\
\text { vector } \\
\text { machine } \\
\text { technique for } \\
\text { classification }\end{array}$ & $\begin{array}{l}100 \text { (with } \\
\text { phone } \\
\text { images) } \\
100 \text { (without } \\
\text { phone } \\
\text { images) }\end{array}$ & $91.57 \%$ \\
\hline [3] & $\begin{array}{l}\text { Deep learning } \\
\text { based Single } \\
\text { Shot Multi } \\
\text { Box Detector( } \\
\text { SSD) model }\end{array}$ & Python & $\begin{array}{l}68 \text { (NIR } \\
+ \text { RGB) } \\
\text { images to } \\
\text { train model } \\
192 \text { images } \\
\text { for } \\
\text { validation }\end{array}$ & $91 \%$ \\
\hline [5] & $\begin{array}{l}\text { 3D } \\
\text { Convolutional } \\
\text { Network }\end{array}$ & $\begin{array}{l}\text { Python, } \\
\text { Tensor flow }\end{array}$ & $\begin{array}{l}\text { NTHU-DD } \\
\text { dataset }\end{array}$ & $97 \%$ \\
\hline [8] & $\begin{array}{l}\text { Face detection } \\
\text { Facial } \\
\text { mapping using } \\
\text { Dlib, } \\
\text { Eye closure } \\
\text { detection, } \\
\text { Yawn } \\
\text { detection }\end{array}$ & $\begin{array}{l}\text { Python, } \\
\text { haar- } \\
\text { classifiers, } \\
\text { Dlib }\end{array}$ & $\begin{array}{l}\text { Test was } \\
\text { done on } 20 \\
\text { subjects }\end{array}$ & $85 \%$ \\
\hline
\end{tabular}

\section{WORKING OF THE SYSTEM}

Input to the system is provided using a web cam or external camera, then frame by frame is pre-processed i.e. image is resized and converted into grayscale image. On that grayscale image facial landmarks are detected using Dlib on the face region. For Drowsiness Detection, using the facial landmarks eye coordinates are taken and the EAR (Eye Aspect Ratio) is calculated for the first time system will set the first frame value of EAR as the threshold EAR. So whenever the EAR falls below threshold it will alert the driver using a sound audio. Also for Mobile Usage Detection, system will detect the object in the hands or near the ear region of the driver. If mobile is detected then it will alert the driver. For Lack of concentration, system will monitor the head movement of the driver. If unnecessary movement is noticed then alert will be given.

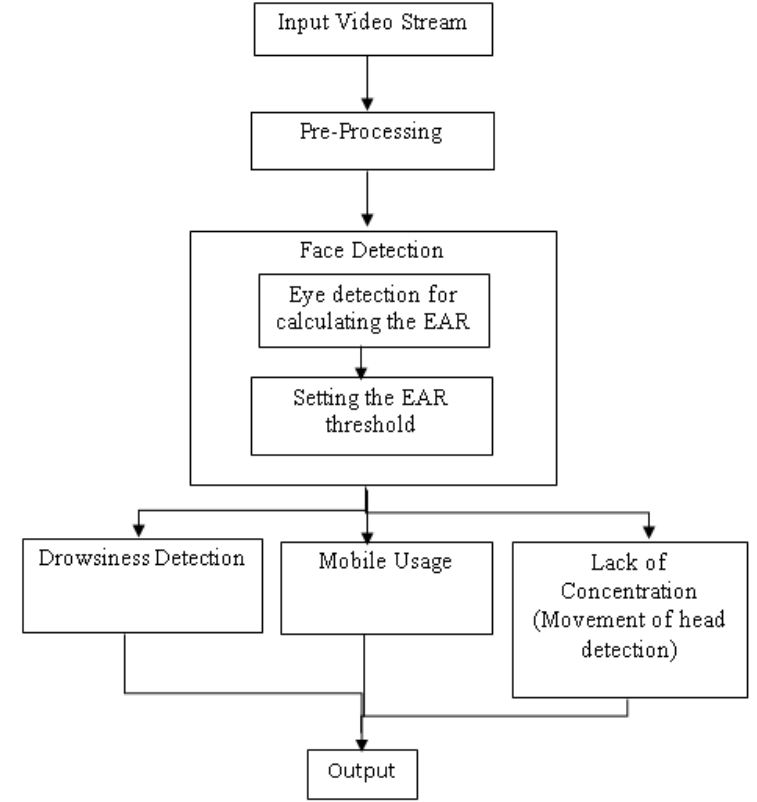

Fig 1: System Block diagram

\subsection{Drowsiness detection}

Input: Video Stream input from the mobile camera fixed to mobile holder on car dashboard.

Output: System will give alert if it detects whether driver's eyes are closed or not, depending on the Eye Aspect Ratio Calculated by the system every time.

Requirements: Dlib Library which will help in Facial landmark detection using convex hull function.

Description: Driver's drowsiness is one of the major cause of road accidents which results in severe physical injuries and also deaths. Drowsiness condition reduces the driver's attention. Fatigue signs which could represent drowsy drivers, such as a driver yawning repeatedly, a driver having difficulty keeping his/her eyes open, and having trouble keeping his/her head up. Image of the driver will be input to the system and that images will be processed by the system for calculating the EAR for detecting whether the eyes are closed or not.

\subsection{Mobile Usage Detection}

Input:Video Stream input from the mobile camera fixed to mobile holder on car dashboard.

Output:System will give alert if it detects whether driver is using mobile phone while driving.

Requirements: Object detection algorithm (support vector machine or single shot multi box detector) for detection of mobile phone near the ear of the driver.

Description: The distraction while driving vehicle can divert the driver's attention from the road for a few seconds. For example, dialing a phone number or text message might take about 5 seconds, in that 5 second vehicle can travel 56 meters if it is at a speed of $40 \mathrm{~km} / \mathrm{hr}$. 


\subsection{Lack of Concentration}

Input: Video Stream input from the mobile camera fixed to mobile holder on car dashboard.

Output: System will give alert if it detects driver's unnecessary head movement (looking left or right) repeatedly while driving.

Requirements: SolvePnP function of OpenCV and three Euler angles of rotation for detection of head position.

Description: The distraction can be of any type. In lack of concentration, the head pose of the driver can be used to find whether the driver is looking straight or not, that is while driving, if unnecessarily he is moving his head repeatedly then our system will give alert. The estimation of head pose will be done using the solvePnP function of the openCv library. World coordinates calculated which is the $3 \mathrm{D}$ coordinates of various face points are used to detect the head pose, then this pose is re-projected from the $3 \mathrm{D}$ coordinate point to the world coordinate axes. The three Euler (roll, pitch and jaw) angles of rotation around three axes are used. After the computation of the Euler angle value of $\mathrm{x}, \mathrm{y}, \mathrm{z}$ of the head position is generated and by tracking the value of $y$, one will be able to determine if the driver is turning his/her head to left or right.

\section{IMPLEMENTATION}

\subsection{Dataset}

The pre-trained facial landmark detector inside the Dlib library is used to estimate the location of 68 (x, y)coordinates that map to facial structures on the face. dlib.get_frontal_face_detector () is used in detecting the face in a frame or image. dlib.shape_predictor() is a tool that takes in an image region containing some object and outputs a set of point locations that define the pose of the object.

ssd_mobilenet_v3_large_coco_2020_01_14

Real-time Objet detection using SSD mobilenet v3 on video streams is performed. SSD is a popular algorithm in object detection while Mobilenet is a convolution neural network used to produce high level features.

An input is given to the system using a web cam or external camera that video frames are pre-processed i.e. resized and converted into the grayscale image. Performing SSD mobilenet on the grayscale image, detection of object is done. On this image finally coco dataset label identification of the object is done.

\subsection{Implementation of Drowsiness detection}

On the processed image the 68 face landmarks are detected using the Dlib and the pre-trained dataset shape_predictor_68_face_landmarks.dat.

The landmark detected eye coordinates of both eyes are taken to calculate the EAR, by which system determines the open and close state of eye.

Then system checks the EAR value with the Threshold and alerts the driver if it's below threshold with the alert audio.

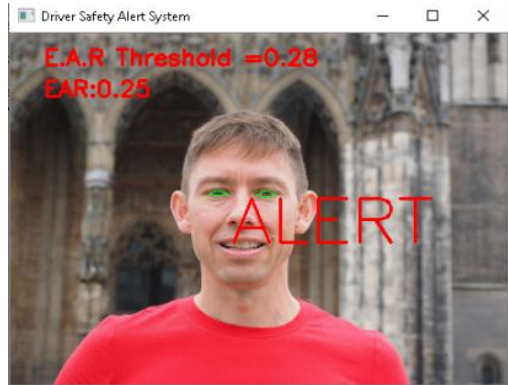

Fig 2: Drowsiness detection

\subsection{Implementation of Lack of Concentration detection}

On the processed image the tip of nose, right and left most point of eye, mouth and jaw line point are detected using the Dlib and the pre-trained dataset.

To obtain rotation matrix, the detected landmarks of the tip of nose, right and left most point of eye, mouth and jawline are given to the solvePnP function which return the success message with rotation vector and translation vector.

To obtain the Matrix, the function called cv2.Rodrigues(rt) is used which convert the rotation vector to rotation matrix.

Next, Euler Angles() are obtained using cv2.RQDecomp3x3(rmat) and headpose can be detected.

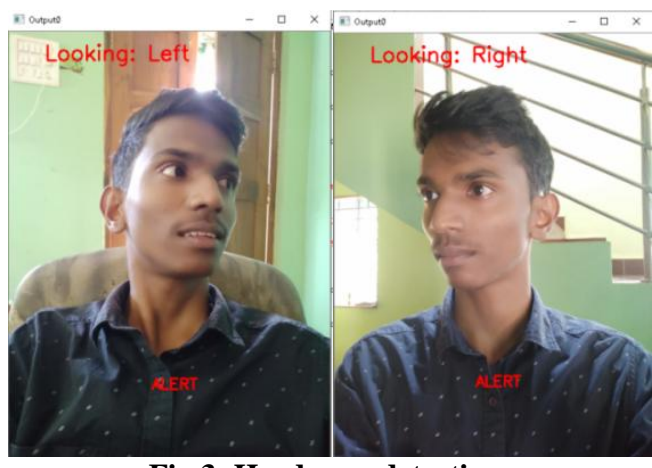

Fig 3: Head pose detection

\subsection{Implementation of Mobile usage} detection

Input image is passed to the detection model for detection of mobile object in the frame. An alert is shown to user if counter reaches threshold.

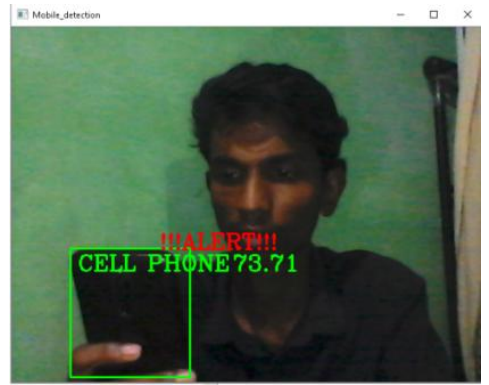

Fig 4: Detection of Mobile object with alert message 


\subsection{Implementation of Combined modules}

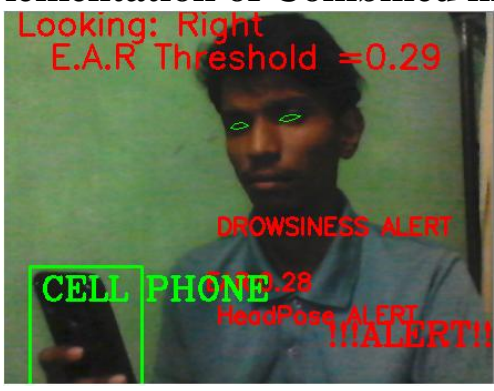

Fig 5. Combined System

\section{PERFORMANCE EVALUATION}

The accuracy of each module is calculated considering various test cases. The overall accuracy of a system considering normal case and with eye glasses is $78.71 \%$.

Table 2. Drowsiness detection testing

\begin{tabular}{|l|l|l|l|l|}
\hline Test Case & $\begin{array}{l}\text { EAR } \\
\text { thresh } \\
\text { old }\end{array}$ & $\begin{array}{l}\text { Total } \\
\text { frames }\end{array}$ & $\begin{array}{l}\text { Frames } \\
\text { detected } \\
\text { with face }\end{array}$ & Accuracy \\
\hline Normal & 0.29 & 1436 & 1195 & $83.21 \%$ \\
\hline $\begin{array}{l}\text { With } \\
\text { eyeglasses }\end{array}$ & 0.28 & 1587 & 1112 & $70.07 \%$ \\
\hline
\end{tabular}

Table 3. Lack of Concentration testing

\begin{tabular}{|l|l|l|l|}
\hline Test Case & $\begin{array}{l}\text { Total } \\
\text { frames }\end{array}$ & $\begin{array}{l}\text { Frames } \\
\text { detected with } \\
\text { face }\end{array}$ & Accuracy \\
\hline Normal & 1195 & 909 & $76.06 \%$ \\
\hline $\begin{array}{l}\text { With } \\
\text { eyeglasses }\end{array}$ & 1286 & 686 & $53.34 \%$ \\
\hline
\end{tabular}

Table 4. Mobile detection testing

\begin{tabular}{|l|l|l|l|}
\hline Test case & $\begin{array}{l}\text { Total } \\
\text { frames }\end{array}$ & $\begin{array}{l}\text { Frames } \\
\text { detected with } \\
\text { mobile }\end{array}$ & Accuracy \\
\hline $\begin{array}{l}\text { Mobile in } \\
\text { front of face }\end{array}$ & 594 & 462 & $77.77 \%$ \\
\hline $\begin{array}{l}\text { Mobile near } \\
\text { ear }\end{array}$ & 394 & 292 & $74.11 \%$ \\
\hline
\end{tabular}

Table 5. Combined modules testing

\begin{tabular}{|l|l|l|l|l|l|}
\hline $\begin{array}{l}\text { Test } \\
\text { case }\end{array}$ & $\begin{array}{l}\text { Total } \\
\text { frames }\end{array}$ & $\begin{array}{l}\text { Frames } \\
\text { detected } \\
\text { for } \\
\text { drowsi- } \\
\text { ness } \\
\text { detection }\end{array}$ & $\begin{array}{l}\text { Frames } \\
\text { detected } \\
\text { for lack } \\
\text { of } \\
\text { concen- } \\
\text { tration }\end{array}$ & $\begin{array}{l}\text { Frames } \\
\text { detecte } \\
\text { d for } \\
\text { mobile } \\
\text { detecti- } \\
\text { on }\end{array}$ & $\begin{array}{l}\text { Overall } \\
\text { Accuracy }\end{array}$ \\
\hline Normal & 469 & 413 & 413 & 370 & $85 \%$ \\
\hline $\begin{array}{l}\text { With } \\
\text { eye } \\
\text { glasses }\end{array}$ & 435 & 349 & 349 & 247 & $72.41 \%$ \\
\hline
\end{tabular}

\section{CONCLUSION}

The drowsiness detection system developed is capable of detecting drowsiness in a rapid manner. The detection of lack of concentration and mobile usage modules developed are also capable of detecting driver's head position as well as the mobile phone in the hands or near the driver's ears. Finally all three modules are merged together and the system works well and gives the expected output. Hence the system helps the driver to drive safely and this leads to reducing the number of road accidents. The drowsiness detection module is a minimum intrusive approach for monitoring driver drowsiness, based on computer vision techniques, installed on a real car, capable of dealing with real operation conditions.

\section{REFERENCES}

[1] Erik Coman, Zhiheng Fan, William Huynh, Daniel Marinetti: Software Requirements Specification for Pedestrian Collision Avoidance System.

[2] Jie Yi Wong and Phooi Yee Lau: "Real-Time Driver Alert System Using Raspberry Pi",ECTI Transactions on Electrical Eng., Electronics and Communication, Vol.17, No.2 August 2019.

[3] BensuAlkan, BurakBalci, AlperenElihos and Yusuf Artan: "Driver Cell Phone Usage Violation Detection using License Plate Recognition Camera Images", 5th International Conference on Vehicle Technology and Intelligent Transport Systems, 2019.

[4] Rafael A. Berri, Alexandre G. Silva, Rafael S. Parpinelli, Elaine Girardi and Rangel Arthur: "A Pattern Recognition System for Detecting Use of Mobile Phones While Driving", Proceedings of the 9th International Conference on Computer Vision Theory and Applications, 2014.

[5] Younes Ed-Doughmi ,NajlaeIdrissi and Youssef Hbali : "Real-Time System for Driver Fatigue Detection Based on a Recurrent Neuronal Network", Journal of Imaging, March 2020.

[6] G.N. Keshava Murthy and Zaved Ahmed Khan: "Smart Alert System for Driver Drowsiness Using Eegand Eyelid Movements", Middle East Journal of Scientific Research • May 2013.

[7] Anurag De, AshimSaha, Dr. M.C Pal: "A Human Facial Expression Recognition Model based on Eigen Face Approach", International Conference on Advanced Computing Technologies and Applications (ICACTA2015).

[8] B. Mohana, C. M. Sheela Rani: "Drowsiness Detection Based on Eye Closure and Yawning Detection", International Journal of Recent Technology and Engineering (IJRTE) ISSN: 2277-3878, Volume-8 Issue4, November 2019.

[9] Rajasekar .R, Vivek Bharat Pattni , S. Vanangamudi : "Drowsy Driver Sleeping Device and Driver Alert System", International Journal of Science and Research (IJSR),ISSN (Online): 2319-7064

[10] YingyuJi, Shigang Wang, Yang Lu, Jian Wei, and Yan Zhao: "Eye and mouth state detection algorithm based on contour feature extraction", Journal of Electronic Imaging 27(5), 051205, Sep/Oct 2018. 